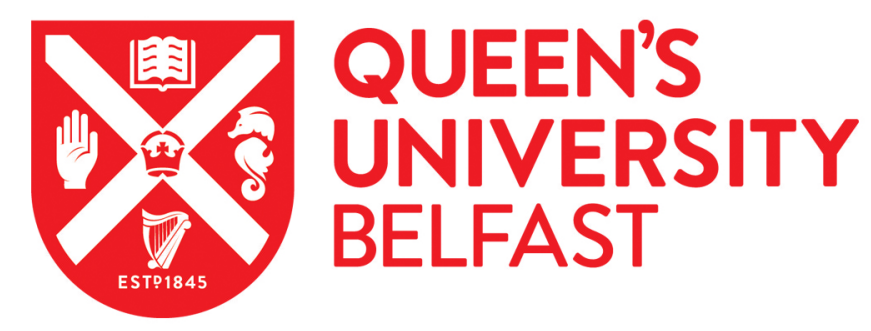

\title{
Validation of a 3D damage model for predicting the response of composite structures under crushing loads
}

Chiu, L. N. S., Falzon, B. G., Chen, B., \& Yan, W. (2016). Validation of a 3D damage model for predicting the response of composite structures under crushing loads. Composite Structures, 147, 65-73. https://doi.org/10.1016/j.compstruct.2016.03.028

\section{Published in:}

Composite Structures

\section{Document Version:}

Peer reviewed version

\section{Queen's University Belfast - Research Portal:}

Link to publication record in Queen's University Belfast Research Portal

\author{
Publisher rights \\ (C) 2016, Elsevier \\ This manuscript version is made available under the CC-BY-NC-ND 4.0 license http://creativecommons.org/licenses/by-nc-nd/4.0/ \\ which permits distribution and reproduction for non-commercial purposes, provided the author and source are cited.
}

\section{General rights}

Copyright for the publications made accessible via the Queen's University Belfast Research Portal is retained by the author(s) and / or other copyright owners and it is a condition of accessing these publications that users recognise and abide by the legal requirements associated with these rights.

\section{Take down policy}

The Research Portal is Queen's institutional repository that provides access to Queen's research output. Every effort has been made to ensure that content in the Research Portal does not infringe any person's rights, or applicable UK laws. If you discover content in the Research Portal that you believe breaches copyright or violates any law, please contact openaccess@qub.ac.uk. 


\title{
Validation of a 3D damage model for predicting the response of composite structures under crushing loads
}

Louis N. S. Chiu ${ }^{1,2}$, Brian G. Falzon ${ }^{3 *}$, Bernard Chen ${ }^{1}$, Wenyi Yan ${ }^{1}$

1, Department of Mechanical and Aerospace Engineering, Monash University, Clayton

Campus, Victoria 3800, Australia

2, Cooperative Research Centre for Advanced Composite Structures, 1/320 Lorimer Street, Port Melbourne, Victoria 3207, Australia

3, School of Mechanical and Aerospace Engineering, Queen's University Belfast, Belfast, BT9 5AH, UK

* Corresponding author: Brian G. Falzon (b.falzon@qub.ac.uk)

Tel: +44 2890975640

\begin{abstract}
A 3D intralaminar continuum damage mechanics based material model, combining damage mode interaction and material nonlinearity, was developed by the authors $[1,2]$ to predict the damage response of composite structures undergoing crush loading. This model captures the structural response without the need for calibration of experimentally determined material parameters. When used in the design of energy absorbing composite structures, it can reduce the dependence on physical testing. This paper validates this model against experimental data obtained from the literature and in-house testing. Results show that the model can predict the force response of the crushed composite structures with good accuracy. The simulated energy absorption in each test case was within $12 \%$ of the experimental value. Post-crush deformation and the damage morphologies, such as ply splitting, splaying and breakage, were also accurately reproduced. This study establishes the capability of this damage model for predicting the responses of composite structures under crushing loads.
\end{abstract}

Keywords: Damage mechanics, Finite element analysis, Crushing response, Energy absorption 


\section{Introduction}

The use of carbon fibre reinforced polymer (CFRP) materials in aerostructures has increased significantly in pursuit of weight savings. This has driven demand for the development of advanced computational modelling techniques to capture the behaviour of composite structures, under crush loading, for crashworthiness assessments.

Finite element-based composite damage models are available in commercial packages. Examples include the material model type 54, implemented in LS-DYNA [3], which utilises an approach based on the failure criterion proposed by Chang and Chang [4]; the ply type 7 model implemented for PAM-CRASH based on Ladeveze and Le Dantec's [5] work; and Abaqus' in-built progressive composite damage model, based on the work by Matzenmiller et al. [6]. However, calibration of non-physical input parameters such as SOFT, FBRT and YCFAC, used in MAT54 (LS-DYNA) to control the damage process, is generally required [7]. This process often entails the physical testing of a representative component in question to provide calibration data. The ability to predict the structural response, based instead on a set of intrinsic material properties, can reduce the reliance on testing and hence reduce the associated costs.

More sophisticated composite damage models have been proposed in recent years. Puck and Schürmann [8] showed that the assessment of matrix damage requires consideration of local interactions. Puck and Schürmann's matrix damage initiation criterion was incorporated into models developed by Donadon et al. [9] and later by Faggiani and Falzon [10]. Their models also captured the inelastic shear behaviour as well as the loading history of the material to account for the highly localised and rapid load redistribution in crush failure of composite structures. Raimondo et al. [11] introduced damage mode interactions through an energybased approach that considered the contribution from each loading direction to the overall strain energy balance. These approaches have led to improvements in the modelling of impact on composite structures. However, such advances have not been applied to crush modelling and existing work in the literature generally use commercially available codes [7, 12-15] 
requiring considerable calibration. Hence, this paper explores the application of advanced damage modelling techniques to predict the crushing behaviour of composite structures without the need for this type of calibration.

A composite damage model was developed by the authors $[1,2]$ to utilise these techniques [811] in the simulation of crushing of self-supporting composite specimens. This model is built on physically-based damage mechanisms and interactions in contrast to the often empirical nature of commercially available codes. Furthermore, this model can yield accurate results using only the measured intrinsic material property data. In comparison, much of the commercially available models utilise one or more parameters which require calibration against experimental data. Eliminating the need to calibrate gives this model a truly predictive capability. The simulated response was validated against experimental data for four different representative test cases of composite energy absorbing structures.

\section{Brief overview of the damage model}

The damage model $[1,2]$ developed by the authors is a continuum damage mechanics (CDM) based smeared crack finite element (FE) model. It integrates a full 3D implementation, an improved characteristic length determination, nonlinear inelastic shear behaviour, a robust unloading/reloading mechanism and a unified matrix damage mechanism in an ABAQUS/Explicit VUMAT user subroutine. The model deals with the presence of damage by softening the material. Two main forms of damage are considered: fibre-dominated and matrix-dominated damage.

The damage response is assumed to be elastic in the longitudinal and transverse directions and inelastic in shear. Monotonically increasing damage parameters: $0 \leq d_{i} \leq 1$; where $i=$ damage mode, are used to characterise the degradation of the composite. The damage initiation is controlled by the material strengths and the damage evolution is controlled by the critical energy release rates. Details of the formulation may be found in [1]. 
The model distinguishes between fibre- and matrix-dominated damage. Fig. 1 shows interacting tensile and compressive fibre-dominated damage when load reversal occurs. With the evolution of tensile damage, represented by path 2 , upon unloading, a reduced secant modulus will be evident, represented by path 3 . This reduced modulus is not necessarily maintained in compression. Tensile damage tends to be dominated by clustered fibre pull-out [16], which under load reversal leading to a compressive stress state, may result in considerable stiffness recovery (path 4). However, damage sustained in compression along path 5 does contribute to the softening of the tensile modulus when load reverts as the formation of kink bands (broken fibres) and matrix damage in the compressive damage mode [16] irreversibly degrades the load path.

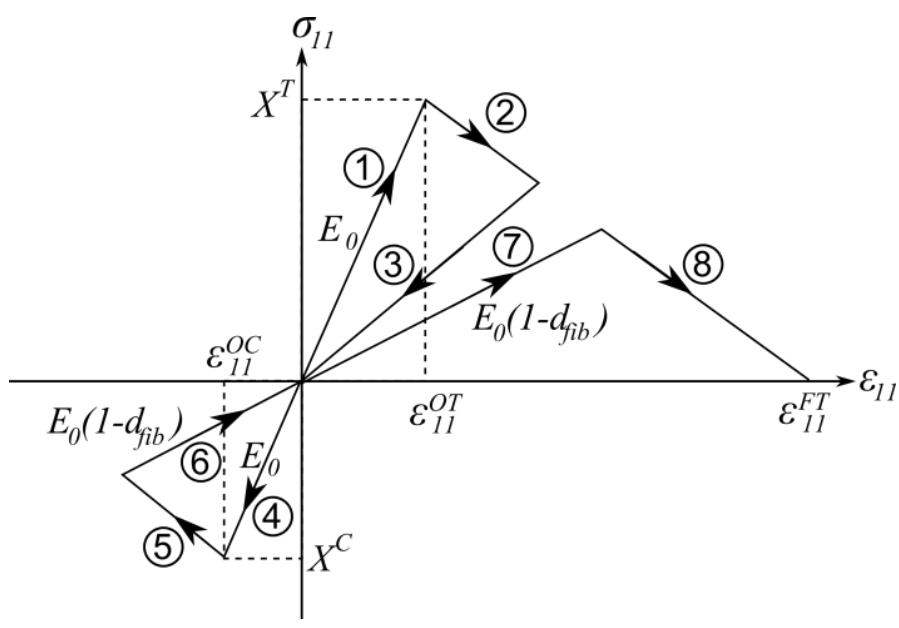

Fig. 1: Stress-strain response during fibre direction loading/unloading.

Matrix-dominated damage is more complex, involving transverse tensile, compressive and shear loading. Matrix-dominated damage occurs via matrix cracking [8] on a fracture plane (Fig. 2), which is at an angle $\theta_{f p}$ with respect to the fibre direction. $\theta_{f p}$ is the angle that maximises the damage initiation criteria $\left(F_{\text {mat }}^{T}\right.$, Eq.1, and $F_{\text {mat }}^{C}$, Eq. 2$)$ ) which are a function of the fracture plane normal stress $\left(\sigma_{N N}\right)$ and shear stresses $\left(\tau_{1 N}\right.$ and $\left.\tau_{N T}\right)$. These criteria control the initiation of damage in the matrix material.

$$
F_{m a t}^{T}=\left(\frac{\sigma_{N N}}{\mathrm{Y}^{\mathrm{T}}}\right)^{2}+\left(\frac{\tau_{N T}}{S_{23}^{A}}\right)^{2}+\left(\frac{\tau_{1 \mathrm{~N}}}{S_{12}}\right)^{2} \quad \text { for } \sigma_{N N}>0
$$




$$
F_{m a t}^{C}=\left(\frac{\tau_{N T}}{S_{23}^{A}-\mu_{N T} \sigma_{N N}}\right)^{2}+\left(\frac{\tau_{1 \mathrm{~N}}}{S_{12}-\mu_{1 \mathrm{~N}} \sigma_{N N}}\right)^{2} \quad \text { for } \sigma_{N N} \leq 0
$$

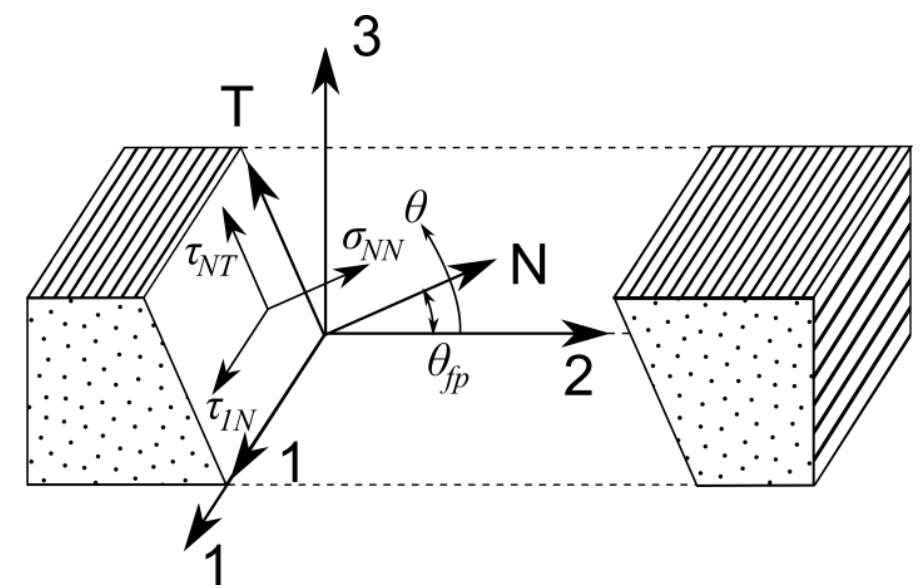

Fig. 2: Coordinate system attached to the fracture plane $(1, \mathrm{~N}, \mathrm{~T})$ relative to the material coordinate system $(1,2,3)$.

Damage progression in the matrix is controlled by the total strain energy release rate ( $G_{\text {mat }}$, Eq. (3)). This is a function of the planar stress state $\left(\sigma_{N N}, \tau_{1 N}, \tau_{N T}\right)$, the corresponding critical energy release rates $\left(G_{m a t}^{C}, G_{m a t}^{12}\right.$ and $\left.G_{m a t}^{23}\right)$, and the $l^{2}$-norm of the stress vector in the fracture plane $\left(\sigma_{r}\right)$.

$$
G_{m a t}=G_{m a t}^{C}\left(\frac{\left\langle\sigma_{N N}\right\rangle}{\sigma_{r}}\right)^{2}+G_{m a t}^{12}\left(\frac{\tau_{1 N}}{\sigma_{r}}\right)^{2}+G_{m a t}^{23}\left(\frac{\tau_{N T}}{\sigma_{r}}\right)^{2}
$$

Element deletion is based on either (i) the damage parameter indicating fibre failure $\left(d_{11}\right)$; or (ii) the magnitude of the deformation gradient $(\operatorname{det}(F))$ to detect large volume changes associated with high element distortion which may lead to numerical instabilities, Eq. (4).

$$
\text { delete element when either }\left\{\begin{array}{c}
d_{11}>0.99 \\
0.8>\operatorname{det}(F) \text { or } \operatorname{det}(F)>1.6
\end{array}\right.
$$

The model was implemented in Abaqus/Explicit [17] as a VUMAT subroutine and coupled with a cohesive contact formulation for capturing delamination. The input data to the simulation consists of intrinsic material properties (elastic moduli, Poisson ratios, strengths, shear profiles and critical energy release rates). 


\section{Mesh objectivity}

The characteristic length was introduced to mitigate the effects of mesh dependence. A simple test case was used to verify the effectiveness of this approach. Fig. $\mathbf{3}$ shows the force response of a cube with different mesh densities under tensile loads. There is very little difference in the recovered constitutive curves. The small deviations close to complete failure arise from infinitesimal strain measure assumption in the damage model. These are not deemed significant.

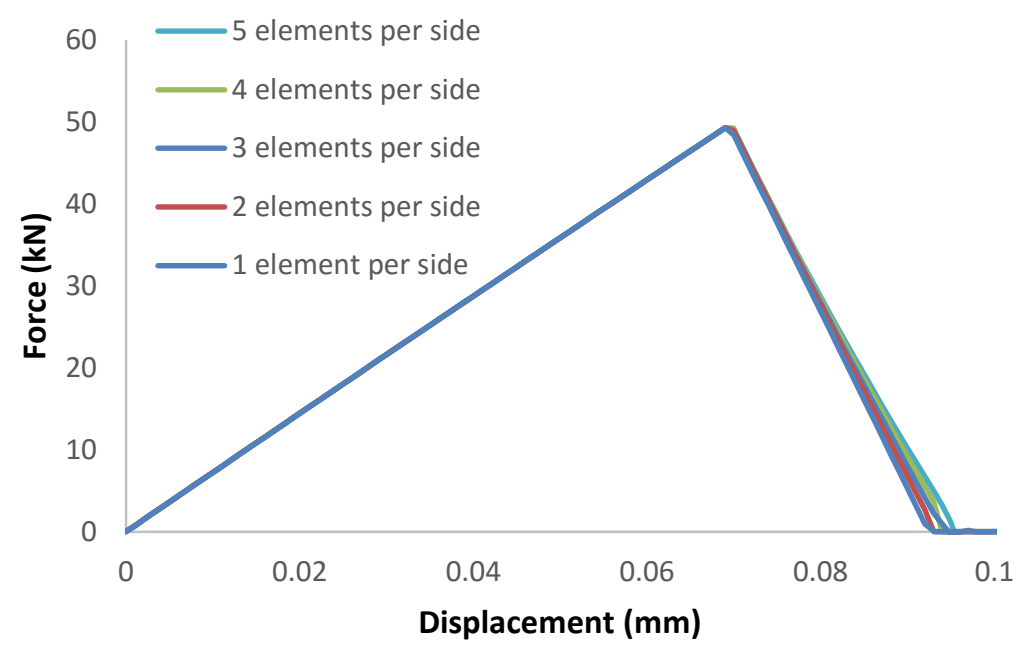

Fig. 3: Force-displacement curves for a simple block with different mesh densities under tensile load.

\section{$4 \quad$ Validation methodology}

\subsection{Test cases and model setup}

Four different test cases are presented for evaluating the predictive capability of the damage model. These test cases encompass different geometries, triggering schemes and layup. Two closed (Fig. 4 and Fig. 5) and two self-supporting open sections (Fig. 6 and Fig. 7) were selected. They represent the type of structures likely to be encountered in the design of energy absorbers. 


\subsubsection{Chamfered cylindrical tube}

The chamfered cylindrical tube (Fig. 4) was chosen as it is one of the simplest designs for a self-supporting energy absorbing composite structure and has been studied extensively [18]. Data from Huang and Wang [19], who tested chamfered cylinders made from T700/QY8911 unidirectional prepreg with a $[+45 /-45 / 90 / 0 / 0 / 90 / 0]_{s}$ layup, was used for validation.
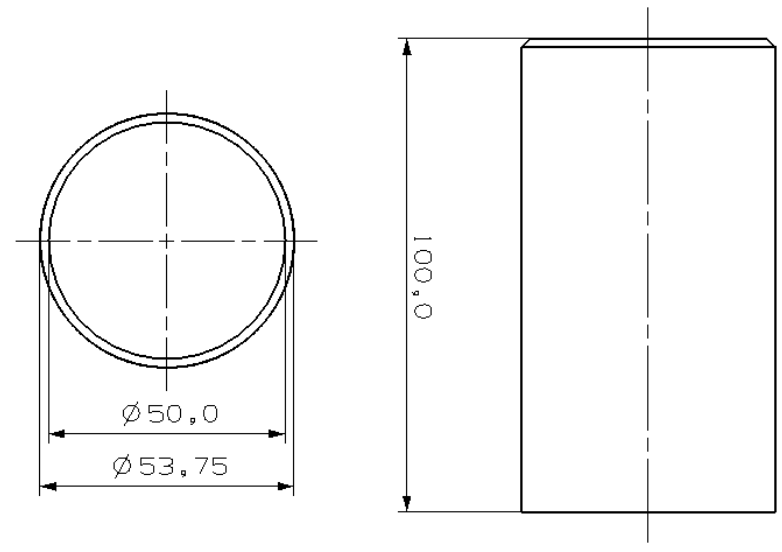

Fig. 4: Chamfered cylinder specimen [19].

\subsubsection{Tulip triggered cylindrical tube}

The inclusion of a tulip trigger in cylindrical tubes (Fig. 5) represents a more flexible design where the initial force response can be tailored to the expected load profile. The force response and damage morphology observed in the testing program, conducted by the authors [20], on specimens manufactured using T700/M21 unidirectional prepreg with a [0/90/0/90]s layup were used for this comparison. 


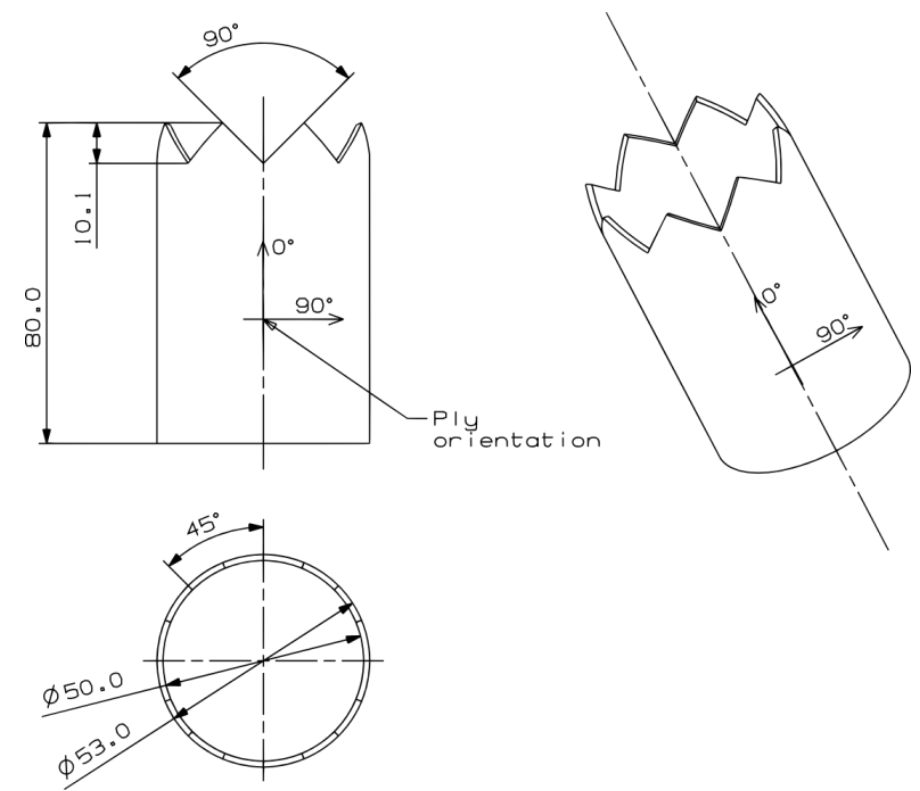

Fig. 5: Tulip triggered cylindrical tube specimen.

\subsubsection{Hat section}

Stiffeners are widely used in aircraft structures and a popular stiffener configuration has a hat shaped cross-section [21]. Experimental data from Joosten et al. [13] for a hat-shaped crush element (Fig. 6) made from woven carbon-epoxy prepreg with a $[0 / 90]_{8}$ stacking sequence was used for comparison with the simulated response.
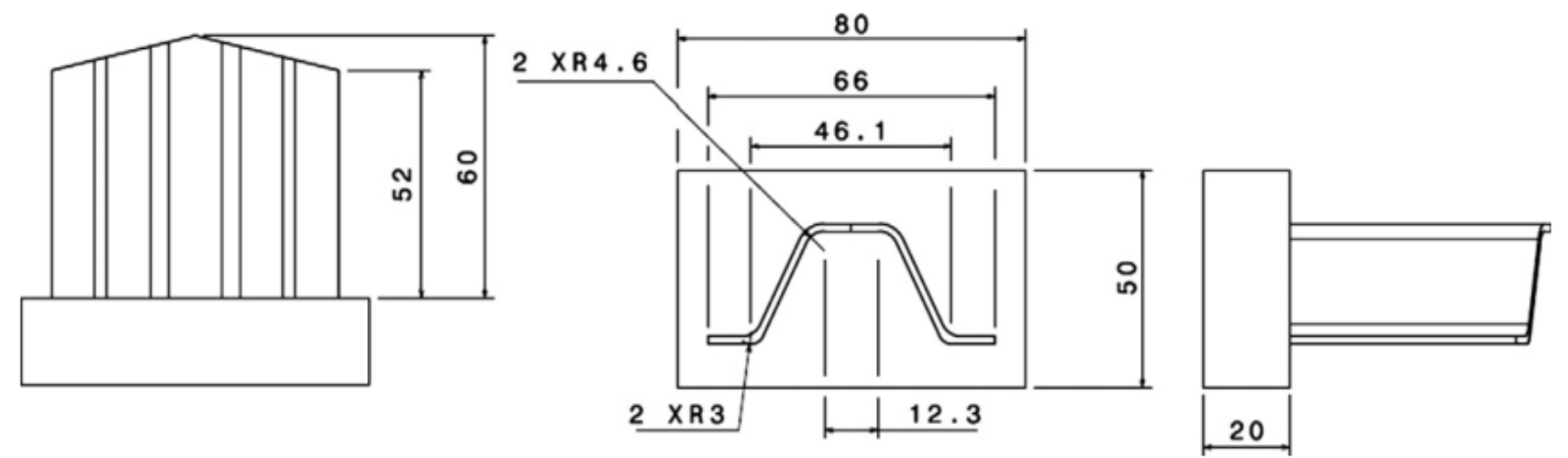

Fig. 6: Steeple triggered hat shaped specimen [13].

\subsubsection{Semi-circular corrugated web}

Corrugated webs have already been used to provide energy absorbing capacity in various aviation [14] and automotive [22] platforms. A semi-circular corrugated web specimen 
manufactured using unidirectional T700/2510 carbon-epoxy prepreg with a $[0 / 90]_{3 S}$ layup was developed and tested by Feroboli [22] (Fig. 7).

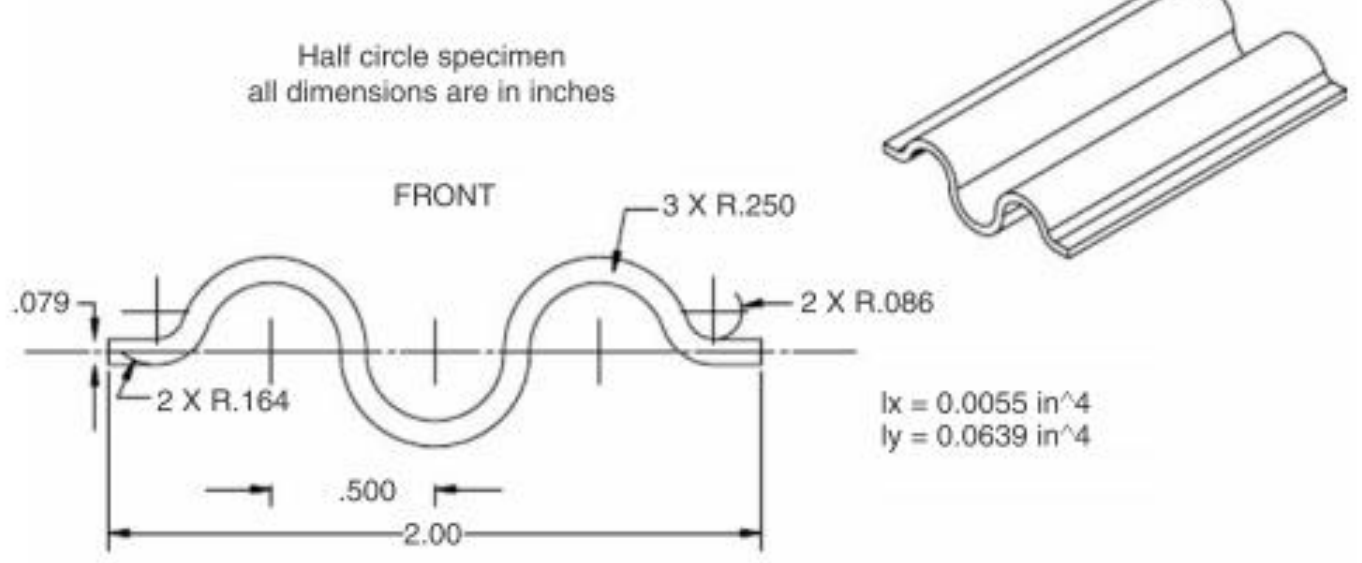

Fig. 7: Semi-circular corrugated web specimen [22] (measurements in inches).

\subsection{Finite element model development}

Three elements through the thickness of each ply were used to accurately represent the bending response of the specimen and cohesive surface laws were used to capture the interlaminar response. Friction was considered for the ply-platen interface as well as between delaminated plies. The experimentally measured friction between the as-cured composite and a machined steel surface was 0.24 , which was used in the trigger region for the tulip-triggered cylinder. However, it is postulated that the lubricating effect of trapped fine graphite debris [23] reduced this to an estimated friction coefficient of 0.10 [24] for CFRP.

The chamfered (Fig. 8a) and the tulip-triggered cylinders (Fig. b) were modelled using quarter symmetry. The hat section (Fig. 8c) was modelled using half symmetry while the corrugated web (Fig. 8d) was modelled in full. 


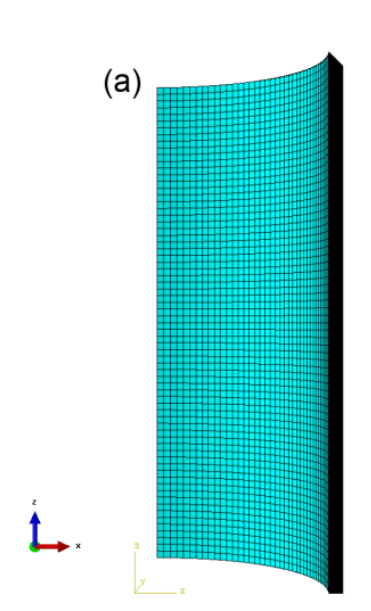

(b)

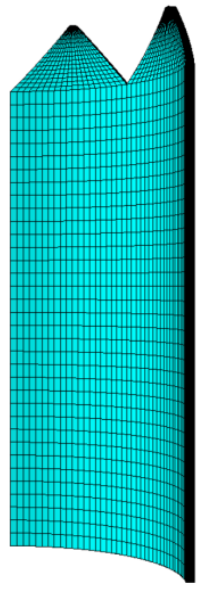

(c)

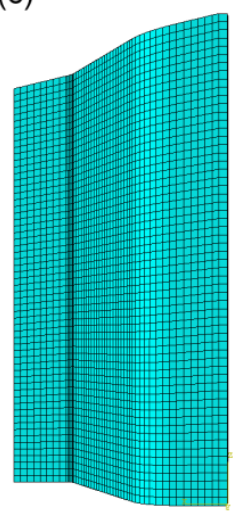

(d)

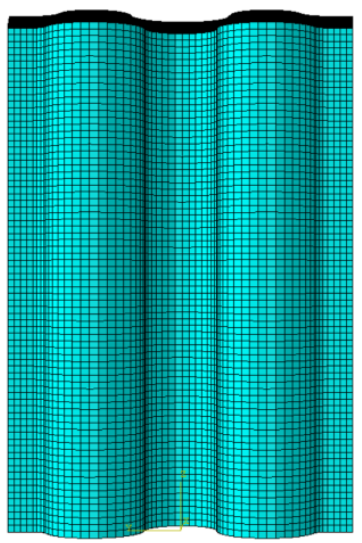

Fig. 8: Mesh configuration for each test case.

All the models were simply-supported at the bottom. A rigid surface, moving at a constant velocity was used to represent the platen. The specimens were meshed using elements approximately 1-2 $\mathrm{mm}$ in length, in the longitudinal and transverse directions. Each ply was three-elements thick to adequately capture the bending behaviour of the ply once delamination has occurred. 3D linear reduced integration solid elements (C3D8R) were used in the mesh. Enhanced hourglass and distortion controls [17] were employed to reduce unphysically large distortions caused by the softening damage model. Mass scaling was used to speed up simulation time. A sensitivity study was conducted to select the parameter controlling the automatic mass scaling process.

Material property data used in this study (Table 1) was sourced from the literature as well as in-house testing. Where specific properties were not available, values for a similar material were used instead. For example, the longitudinal tensile and compressive critical energy release rates for T700/M21 unidirectional carbon-epoxy prepreg were used in place of that for T700/2510 unidirectional carbon-epoxy prepreg. All of the properties were used directly in the simulations and no calibration was conducted on these values.

Table 1: Material property data for the chamfered cylinder (CC), tulip-triggered cylinder (TC), hatsection (HS) and corrugated web (CW) models.

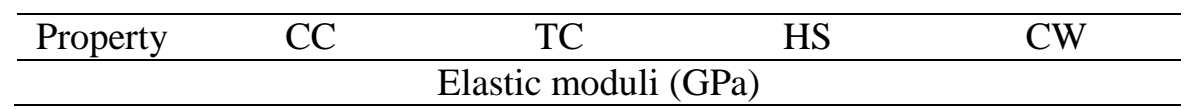




\begin{tabular}{|c|c|c|c|c|}
\hline$E_{11}$ & $135[19]$ & $142[25]$ & $138[26]$ & $127[7]$ \\
\hline$E_{22}$ & $9.12[19]$ & 8.4 [25] & $8.42[26]$ & $8.41[7]$ \\
\hline$E_{33}$ & $9.12[19]$ & 8.4 [25] & 8.42 [26] & $8.41[7]$ \\
\hline \multicolumn{5}{|c|}{ Poisson's ratios } \\
\hline$v_{12}$ & $0.31[19]$ & $0.32[25]$ & $0.257[26]$ & $0.309[7]$ \\
\hline$v_{23}$ & $0.31[19]$ & $0.32[25]$ & $0.387[26]$ & $0.309[7]$ \\
\hline$v_{13}$ & $0.31[19]$ & $0.32[25]$ & $0.257[26]$ & $0.309[7]$ \\
\hline \multicolumn{5}{|c|}{ Shear moduli (MPa) } \\
\hline$G_{12}$ & $5670[19]$ & $4600[25]$ & $3930[26]$ & $4210[7]$ \\
\hline$G_{23}$ & $5670[19]$ & $3950[25]$ & $3030[26]$ & $4210[7]$ \\
\hline$G_{13}$ & $5670[19]$ & $4600[25]$ & $3930[26]$ & $4210[7]$ \\
\hline \multicolumn{5}{|c|}{ Failure strengths (MPa) } \\
\hline$X^{T}$ & 2326 [19] & $2282[25]$ & $1496[26]$ & $2200[7]$ \\
\hline$X^{C}$ & 1236 [19] & $1465[27]$ & $1026[26]$ & $1470[7]$ \\
\hline$Y^{T}$ & $51[19]$ & $65[25]$ & $90[26]$ & $48.9[7]$ \\
\hline$Y^{C}$ & 209 [19] & $290[25]$ & $211[26]$ & 199 [7] \\
\hline$S_{12}$ & 87.9 [19] & $105[25]$ & $77[26]$ & $154[7]$ \\
\hline \multicolumn{5}{|c|}{ Critical energy release rates $\left(\mathrm{mJ} / \mathrm{mm}^{2}\right)$} \\
\hline$G_{f i b}^{T}$ & $108^{*}$ & $108^{\wedge}$ & $91[26]$ & $108^{*}$ \\
\hline$G_{f i b}^{C}$ & $58.4^{*}$ & $58.4^{\wedge}$ & 79 [26] & $58.4^{*}$ \\
\hline$G_{m a t}^{T}$ & $0.425[28]$ & $0.331[29]$ & $0.15[26]$ & $0.504[30]$ \\
\hline$G_{\text {mat }}^{C}$ & $1.1^{*}$ & $1.1^{*}$ & $0.45[26]$ & $1.1^{*}$ \\
\hline$G_{\text {mat }}^{12}$ & $0.587[28]$ & $0.443[29]$ & $2.5[31]$ & $1.566[30]$ \\
\hline$G_{\text {mat }}^{13}$ & $0.587[28]$ & $0.443[29]$ & $2.5[31]$ & $1.566[30]$ \\
\hline$G_{\text {mat }}^{23}$ & $0.587[28]$ & $0.443[29]$ & $2.5[31]$ & $1.566[30]$ \\
\hline \multicolumn{5}{|c|}{ Shear profile coefficients (MPa) } \\
\hline$S_{12}: c_{1}$ & $34238^{*}$ & $34238[32]$ & $636331[31]$ & $34238 *$ \\
\hline$S_{12}: c_{2}$ & $15061^{*}$ & $15061[32]$ & $97193[31]$ & $15061 *$ \\
\hline$S_{12}: c_{3}$ & $2198^{*}$ & $2198[32]$ & $5517[31]$ & $2198^{*}$ \\
\hline$S_{23}: c_{1}$ & $34238^{*}$ & $34238[32]$ & $636331[31]$ & $34238 *$ \\
\hline$S_{23}: c_{2}$ & $15061 *$ & $15061[32]$ & $97193[31]$ & $15061 *$ \\
\hline$S_{23}: c_{3}$ & $2198^{*}$ & $2198[32]$ & $5517[31]$ & $2198^{*}$ \\
\hline$S_{13}: c_{1}$ & $34238^{*}$ & 34238 [32] & $636331[31]$ & $34238^{*}$ \\
\hline$S_{13}: c_{2}$ & $15061 *$ & $15061[32]$ & $97193[31]$ & $15061 *$ \\
\hline$S_{13}: c_{3}$ & $2198 *$ & $2198[32]$ & $5517[31]$ & $2198^{*}$ \\
\hline \multicolumn{5}{|c|}{ Interlaminar fracture energies $\left(\mathrm{mJ} / \mathrm{mm}^{2}\right)$} \\
\hline Inter $G_{I}$ & $0.425[28]$ & $0.331[29]$ & $0.15[26]$ & $0.504[30]$ \\
\hline Inter $G_{I I}$ & $0.587[28]$ & $0.443[29]$ & $2.5[31]$ & $1.566[30]$ \\
\hline \multicolumn{5}{|c|}{ Interlaminar strengths (MPa) } \\
\hline Inter $\sigma_{I}$ & $80 *$ & $60[33]$ & $64[31]$ & $54[30]$ \\
\hline Inter $\sigma_{I I}$ & $60 *$ & $60[33]$ & $80[31]$ & $70[30]$ \\
\hline \multicolumn{5}{|c|}{ Densities $(\mathrm{g} / \mathrm{cc})$} \\
\hline$\rho$ & $1.6 \mathrm{e}-9 *$ & $1.6 \mathrm{e}-9 *$ & $1.5 \mathrm{e}-9[31]$ & $1.6 \mathrm{e}-9[30]$ \\
\hline
\end{tabular}

* Estimated value, ${ }^{\wedge}$ value obtained from in-house testing 


\section{Comparison between numerical and experimental results}

In this section, both the quantitative and the qualitative aspects of the numerical results are compared against experimental data. The quantitative assessment includes the forcedisplacement response as well as the total energy absorbed, both of which are critical measures in energy absorber performance. Selective filtering was employed to remove high frequency noise present in the numerical results. Qualitative assessment includes the post crush shape and damage morphology.

\subsection{Chamfered cylinder}

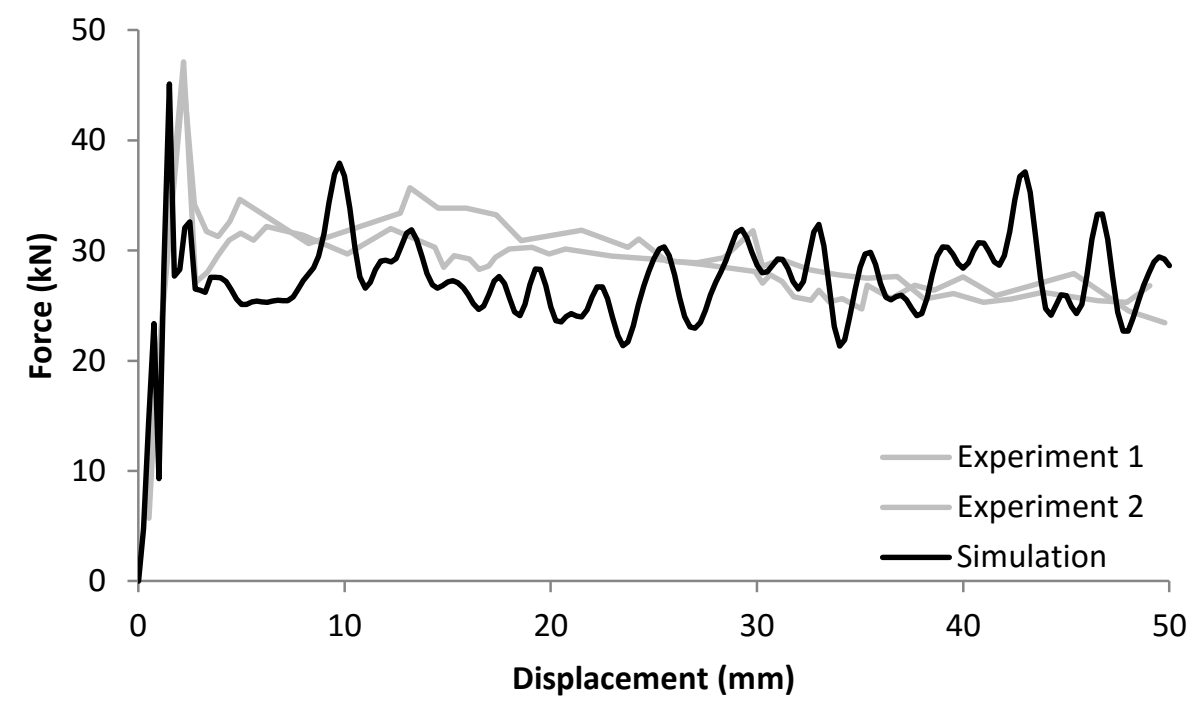

Fig. 9: Comparison of experimentally measured (grey) and simulated (black) force response of chamfered cylindrical tube [19].

The experimentally observed initial peak $(47 \mathrm{kN})$ was well captured by the numerical simulation (45 kN), as shown in Fig. 9. After the initial peak, steady state crushing occurred as expected. The steady state crushing force was also well captured by the numerical model and found to be in agreement with the experimental steady state force of approximately $30 \mathrm{kN}$. The numerically obtained total energy absorption was $1.37 \mathrm{~kJ}$, which compared well with energies of $1.44 \mathrm{~kJ}$ and $1.40 \mathrm{~kJ}$ respectively for the two tests conducted. 


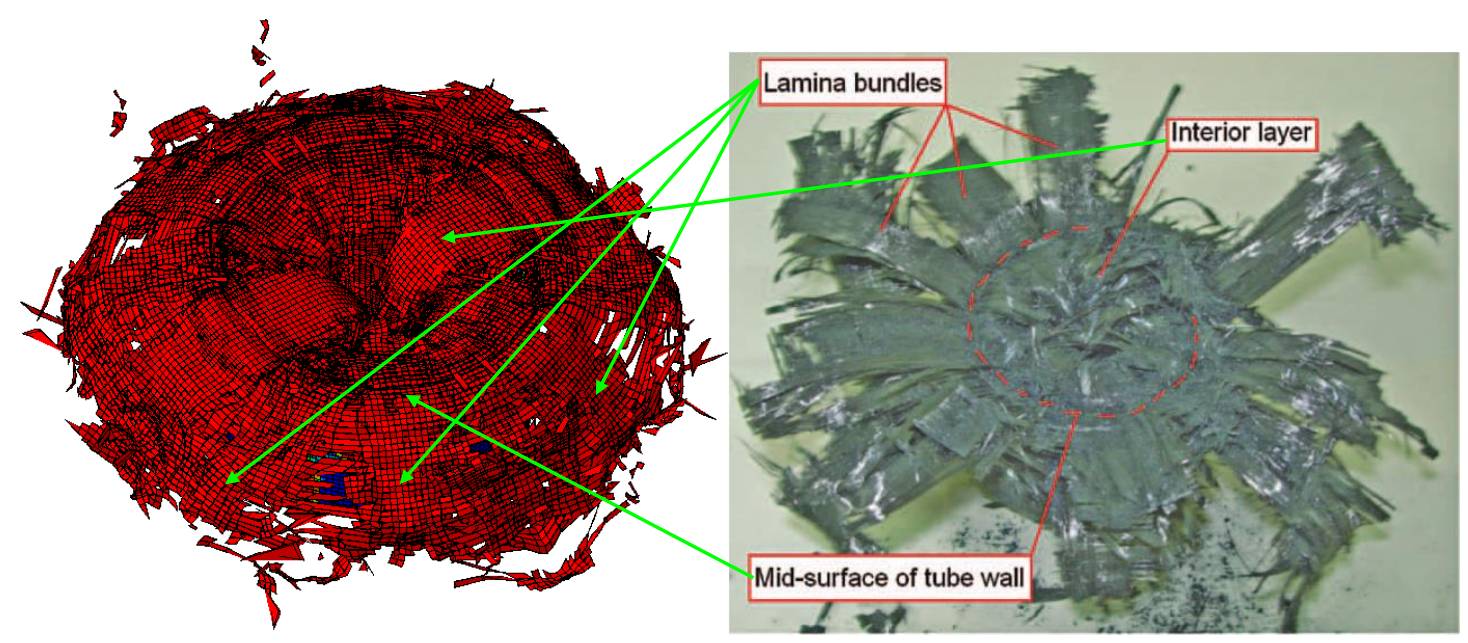

Fig. 10: Comparison of damage morphology between simulated result (left) and experimental observation (right).

The predicted deformation of the specimen was highly consistent with observations (Fig. 10). Multiple "lamina bundles" were formed from the splitting of the ply along the axial direction. Such splitting was evident in both inwards and outwards splaying plies. A clear V-shaped trench marked the mid-surface of the laminate by the splaying plies. Substantial amount of partially attached fragments observed experimentally was also reproduced in the simulation.

\subsection{Tulip triggered cylinder}

The experimentally observed response of the tulip-triggered cylinder correlated well with simulation (Fig. 11). The simulated response closely followed the linearly increasing force response during the consumption of the tulip trigger as well as the constant force response during steady-state crushing. The simulated energy absorption of $479 \mathrm{~J}$ agreed very well with those measured experimentally (between $465 \mathrm{~J}$ and $495 \mathrm{~J}$ ). 


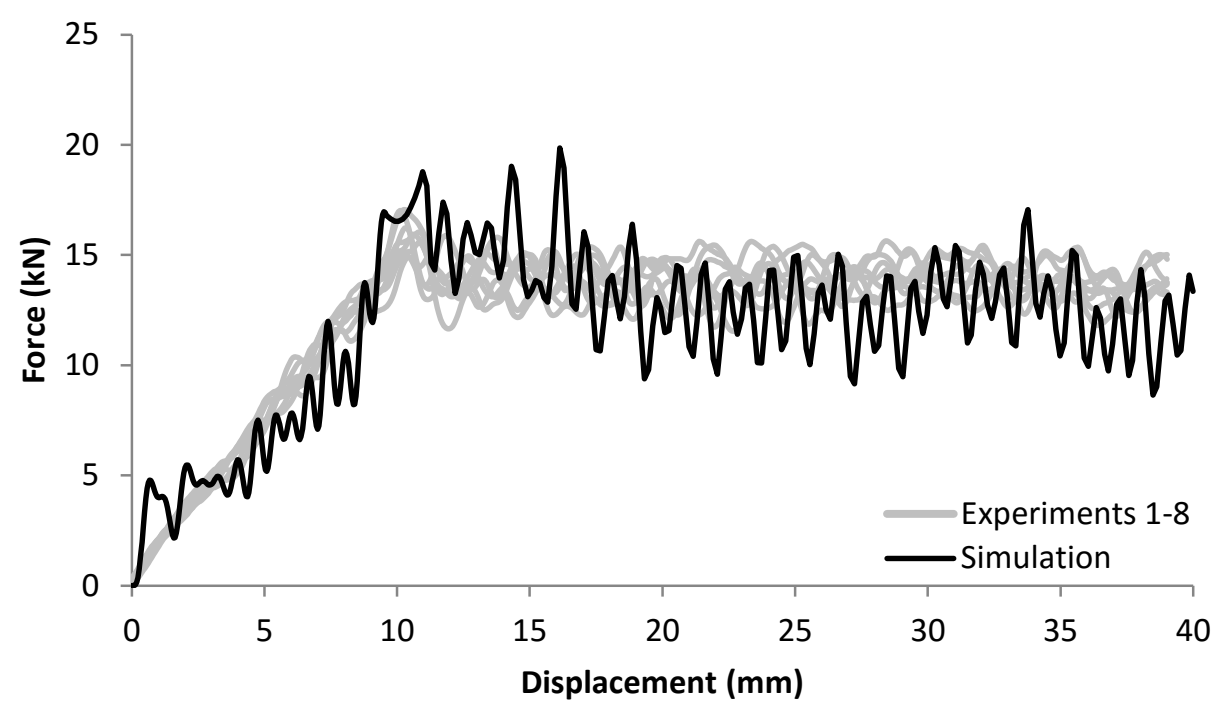

Fig. 11: Comparison of experimentally measured (grey) and simulated (black) force response of tulip triggered cylindrical tube.

Two artificial peaks were observed in the numerical results. The first peak occurred when the specimen first made contact with the platen and the second occurred shortly after the change in friction coefficient to simulate the effect of accumulating composite debris.

The numerical model also successfully predicted the deformation and the spread of the different damage modes through the specimen (Fig. 12). Damage initiated at the tips and spread with the crush front as expected. The extent of damage to the matrix of the $90^{\circ}$ plies, observed in the experiment, was well captured in the simulated specimen (region with matrix damage in Fig. 12 shown in red). The multiple splitting of the inner-most and outer-most $0^{\circ}$ plies was also evident in the simulation. 


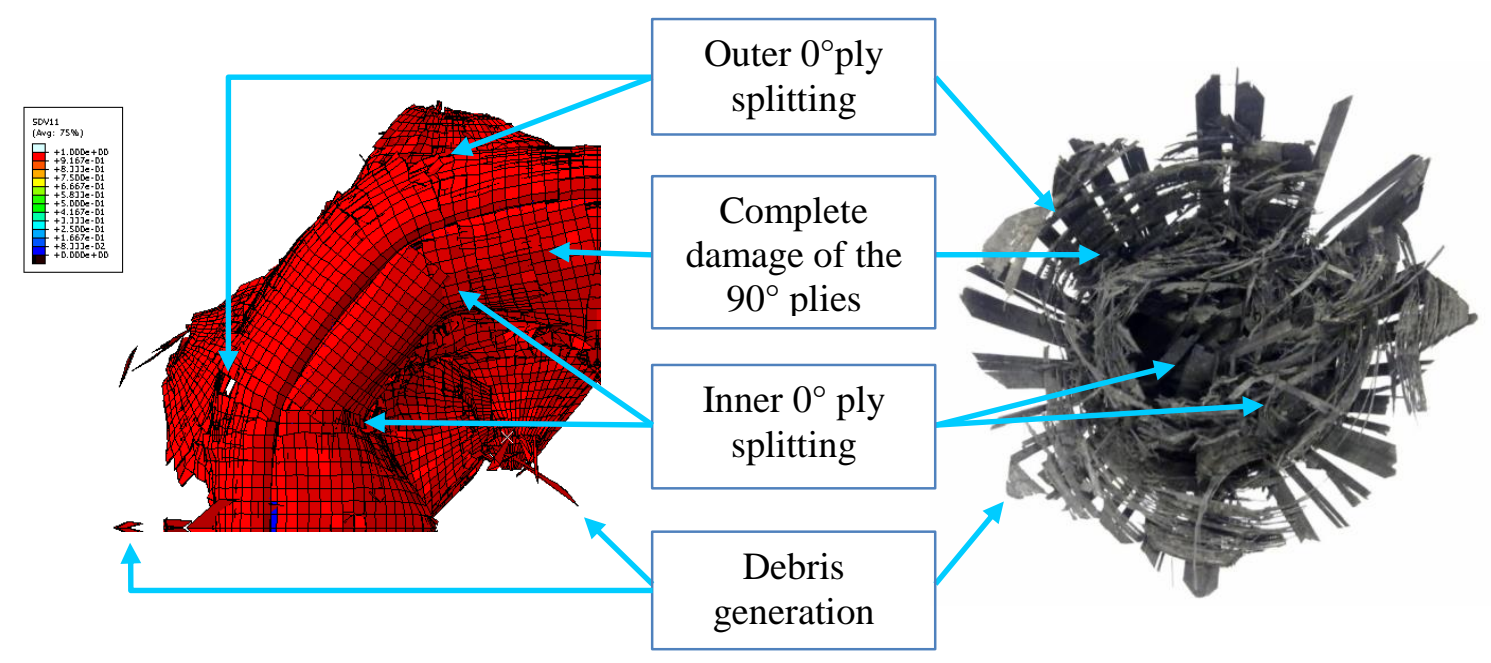

Fig. 12: Top view comparison of simulated (left, quarter symmetric FE model) and experimental (right) damage morphology.

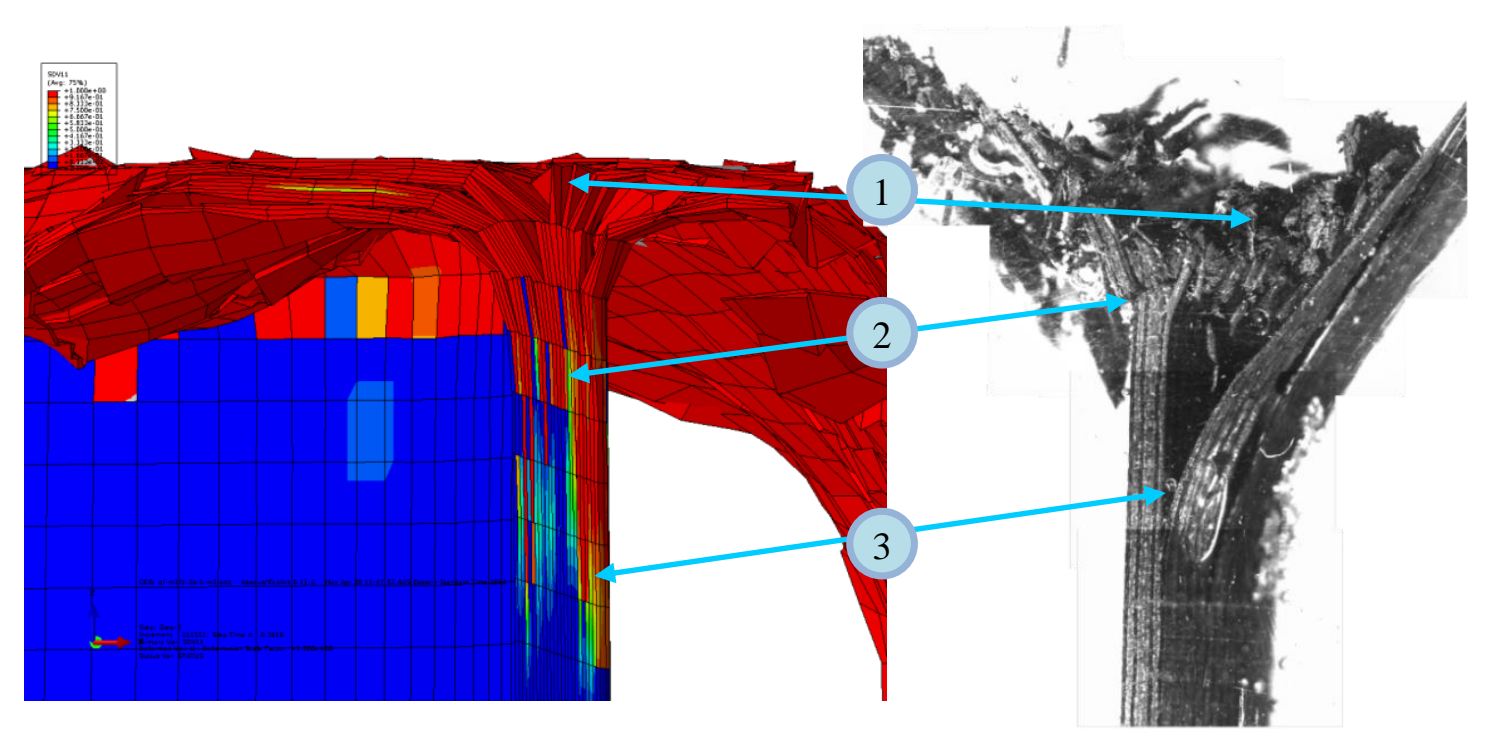

Fig. 13: Cross-sectional view of the laminate near the crush front in the simulated (left) and experimental (right) specimen.

In particular, the simulation was able to resolve the meso-scale damage morphology present within the laminate near the crush front observed through microscopy of the experimental specimen. Fig. 13 shows: (1) debris formation with widespread matrix damage; (2) a flat crush front and (3) outer ply delamination and matrix damage advancing ahead of the crush front. 


\subsection{Hat section}

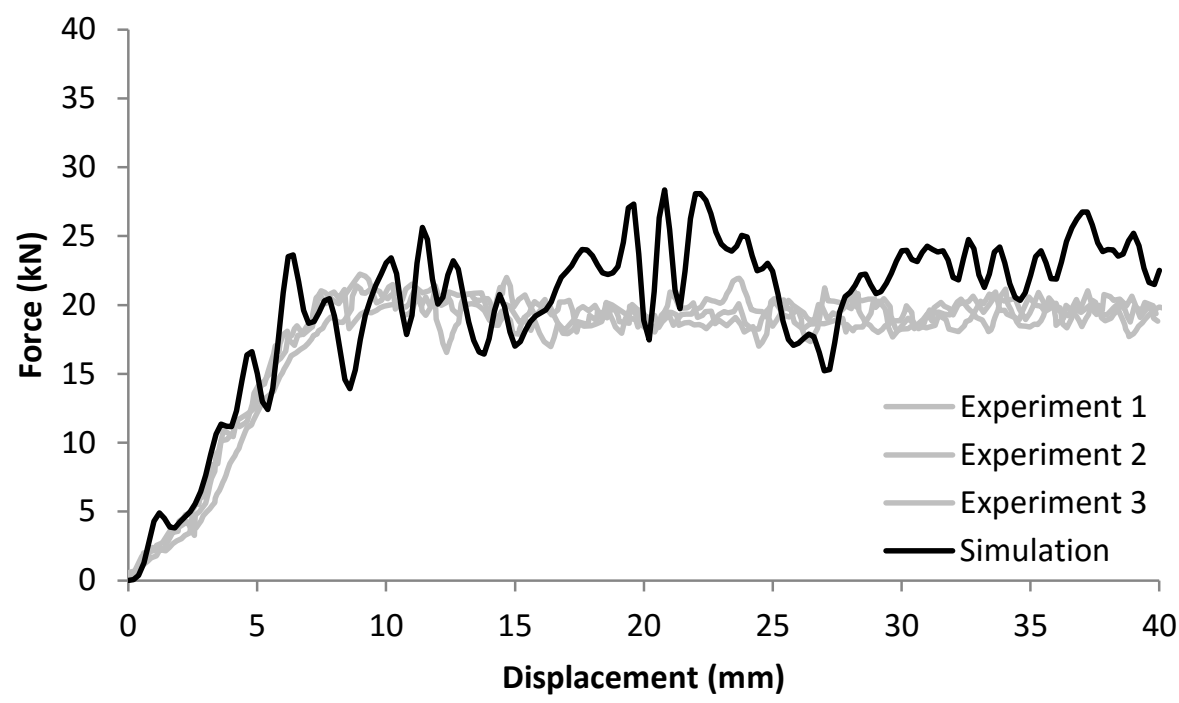

Fig. 14: Comparison of experimentally measured (grey) and simulated (black) force response of the hat-section specimen.

The simulated force response of the hat section specimen followed that of the experimental response (Fig. 14). The numerical and experimental triggering and the steady-state progression of the crush process agreed well. The simulated energy absorption of $804 \mathrm{~J}$ was higher than the experimental average of $704 \mathrm{~J}$. Some low frequency oscillations were evident in the force response.

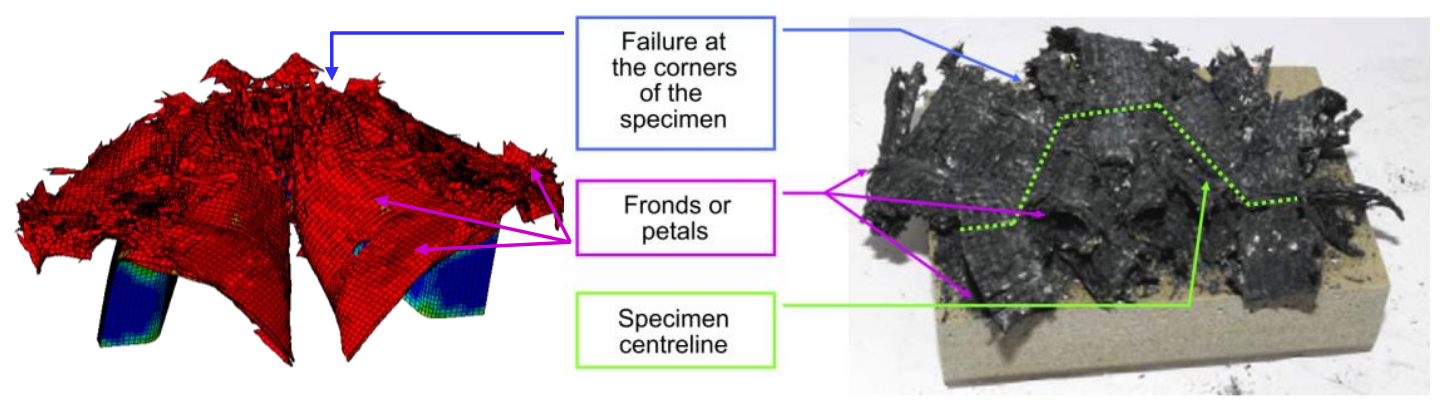

Fig. 15: Comparison of ply damage between simulation (left, reconstructed from half symmetric FE model) and experiment [13] (right).

The damage morphology obtained from the simulation (Fig. 15 (left), red denoting matrixdominated damage) shared many similarities with experimental observation. . Large petals 
were produced from the crushing of the flat surfaces, consistent with observation. However, it is noted that the simulation produced larger petals than what was observed. The model showed improved numerical stability, when compared with closed sections, with a smooth, progressive damage progression.

\subsection{Semi-circular corrugated web}

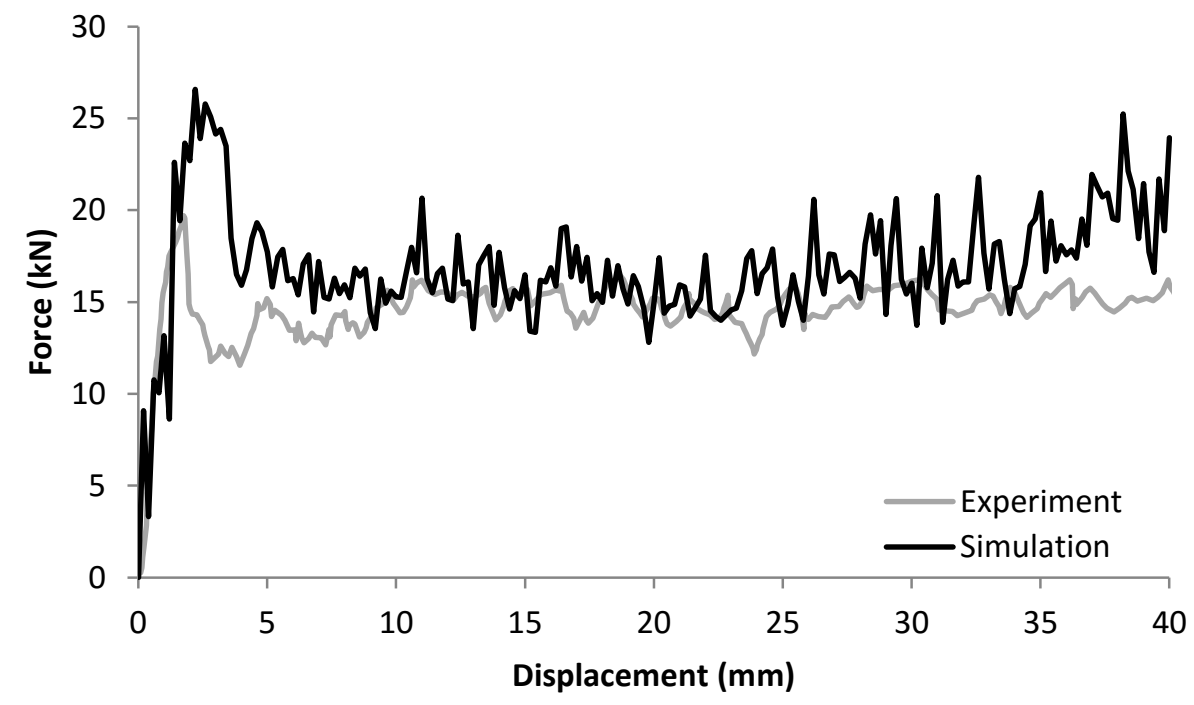

Fig. 16: Comparison of experimentally measured [7] (grey) and simulated (black) force response of the corrugated web.

Fig. 16 shows that the simulation produced a steady-state force response which compared well with experimental measurements but the numerical peak force was over-predicted. The modest increase in energy absorption $(677 \mathrm{~J})$ of the numerical model in comparison with the experimentally measured $631 \mathrm{~J}$ was mostly the result of this over-prediction in peak force. Low level oscillatory noise was also present, with occasional higher amplitude spikes. 


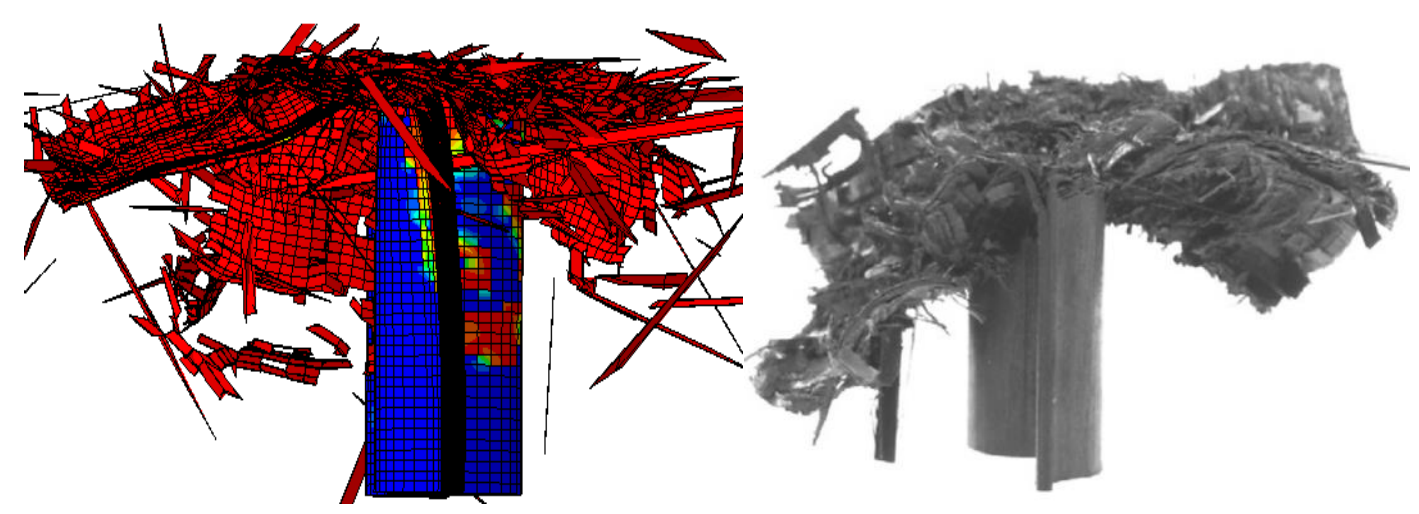

Fig. 17: Comparison of ply damage and debris generation between simulation (left, red denoting matrix-dominated damage) and experiment [7] (right).

The simulated response closely matched the ply damage and debris generation observed in the experimental tests (Fig. 17). Delamination and subsequent splaying of constituent plies was the main form of deformation in both the simulated and experimental response. The variety of different sized debris generated during the splaying process was also mirrored in the simulated results.

\section{Discussions}

\subsection{Predicting force responses and energy absorption}

The initial response of each specimen was well predicted by the numerical model. The steadystate force response, which accounts for the majority of the crush stroke, was particularly well captured for each specimen. This led to a good assessment of the total energy absorption capacity of the different geometries during crush loading. However, oscillatory spikes were present in the force responses of the specimens. These spikes are the result of the deletion algorithm for severely degraded elements. This issue can be alleviated through increasing the mesh density at the expense of increased computational requirement. For example, moving from $2 \mathrm{~mm}$ to $1 \mathrm{~mm}$ sided elements for the chamfered cylinder reduced the average magnitude of oscillatory noise by approximately $50 \%$.

The different geometries were generally well handled as the experimentally observed damage morphologies were well predicted in the simulations. However, very sharp geometric features 
such as the peaks of the tulip triggers and chamfered edges caused certain challenges. The sharp tips caused the over-prediction of the force response during the first millimetre of crush stroke in the tulip-triggered specimen. This was a result of using degraded and deleted elements to represent damage, which means damage can only be resolved to the size of one element. This issue should diminish as the damage zone increases in size. Increasing mesh density will also improve the response in this regard by reducing the area of the smallest resolvable region of damage.

From the force response, the total energy absorption can be calculated. The energy absorption returned by the simulations closely matched experimental observation as shown in Fig. 18 .

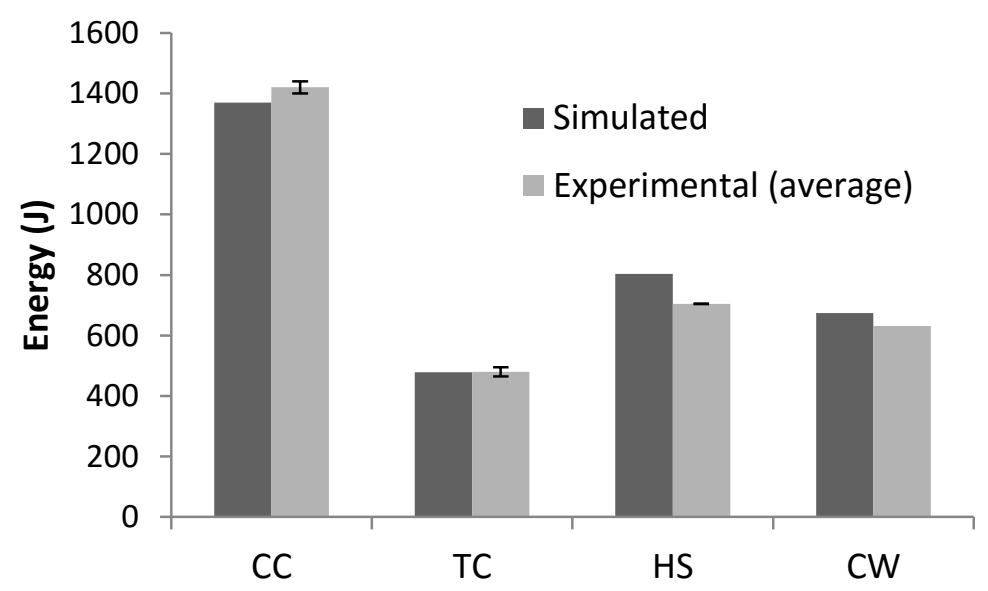

Fig. 18: Comparison of simulated and experimentally measured total energy absorption (error bar indicating range of experimental measurements).

The two cylindrical sections yielded the best results, with $<4 \%$ difference between simulated and experimental results. This is followed by the corrugated web, which has a $6 \%$ difference. The hat-section yielded a result which was $12 \%$ larger than that measured experimentally. It is possible that the difference is due to the lower inherent stability of the geometry. The larger flanges on the sides of the hat sections were not well constrained and prone to global bending instead of splaying which can change the active damage mode locally and hence affecting the resultant energy absorption. 


\subsection{Predicting damage morphologies}

The damage morphology of the simulated specimens closely mirrored experimental observations in all test cases. A large variety of different features was reproduced numerically, ranging in size from large sections of petalling plies to small debris being ejected from the main body. The splaying of the composite laminate under crush loading, which is a critical feature of the damage process, was also well represented. As each ply was modelled individually, the meso-scale effects could also be adequately captured. However, the stiffness of the damaged laminate was somewhat lower than reality, as demonstrated by the limp appearance of the splayed laminate sections in the chamfered and tulip-triggered tubes. This phenomenon is a consequence of the CDM homogenisation formulation, which approximates the numerous intralaminar fractures and voids as a softening of the ply element.

\subsection{Assumptions made and their consequences}

The finite element process assumes that the specimen and material are free from manufacturing variations and imperfections. This can have an impact on the accurate reproduction of the trigger region behaviour, which is more susceptible to these deviations. This may have been a factor in the $28 \%$ over-prediction of the peak force in the corrugated web specimen, as chamfering on an irregular surface may have caused some delamination in the adjacent material.

\subsection{Obtaining material parameters}

Accurate material parameters are crucial to producing the correct response. In particular, the intralaminar critical energy release rates for each damage mode underpin the response of the composite structure. Laffan et al. [16] noted the variability in the experimentally measured intralaminar critical energy release rates due to the difficulty in isolating the desired damage mode. Variability in these values can adversely affect the performance of the damage model and degrade its predictive power. Another important parameter is the friction coefficient between different surfaces that come into contact. As crushing progresses, fine graphite debris 
is generated which alters the properties of the contact interface. This changing contact condition plays a significant role in the overall crush response of the structure.

\section{Conclusions}

A 3D computational intralaminar damage model was developed to accurately predict the crush behaviour of composite structures without the need for input parameter calibration. This study confirms that this damage model has the capacity to simulate composite structures under crush loading with satisfactory results. In addition, these results were obtained using only the geometry and measured intrinsic material properties of the structure. Thus, the utility of the model in reducing physical testing required is demonstrated. The model was benchmarked against experimental results obtained from both in-house testing and the literature. Four representative composite energy absorbing structures were chosen as test cases: a chamfered cylindrical tube, a tulip-triggered cylindrical tube, a hat-shaped section and a semi-circular corrugated web. The force responses were well predicted by the simulation and the total energy absorption in the crushing process compared well with experimental measurements. The predicted deformation and damage morphology of the specimens also compared well with experimental observations.

\section{Acknowledgments}

This work was undertaken within the Systems for Crashworthiness project, part of a CRCACS research program, established and supported under the Australian Government's Cooperative Research Centres Program. Prof Brian G. Falzon acknowledges the financial support of Bombardier and the Royal Academy of Engineering.

\section{References}

[1] Chiu LNS, Falzon BG, Boman R, Chen B, Yan W. Finite element modelling of composite structures under crushing load. Composite Structures. 2015;131:215-28. [2] Tan W, Falzon BG, Chiu LNS, Price M. Predicting low velocity impact damage and Compression-After-Impact (CAI) behaviour of composite laminates. Composites Part A: Applied Science and Manufacturing. 2015;7:212-26.

[3] Hallquist JO. LS-DYNA theory manual. Livermore: Livermore Software Technology Corporation, 2006. 
[4] Chang F-K, Chang K-Y. A Progressive Damage Model for Laminated Composites Containing Stress Concentrations. Journal of Composite Materials. 1987;21:834-55.

[5] Ladeveze P, LeDantec E. Damage modelling of the elementary ply for laminated composites. Composites Science and Technology. 1992;43:257-67.

[6] Matzenmiller A, Lubliner J, Taylor RL. A constitutive model for anisotropic damage in fiber-composites. Mechanics of Materials. 1995;20:125-52.

[7] Feraboli P, Wade B, Deleo F, Rassaian M, Higgins M, Byar A. LS-DYNA MAT54 modeling of the axial crushing of a composite tape sinusoidal specimen. Composites Part A: Applied Science and Manufacturing. 2011;42:1809-25.

[8] Puck A, Schürmann H. Failure analysis of FRP laminates by means of physically based phenomenological models Composites Science and Technology. 1998;58:104567.

[9] Donadon MV, Iannucci L, Falzon BG, Hodgkinson JM, Almeida SFMd. A progressive failure model for composite laminates subjected to low velocity impact damage. Computers and Structures. 2008;86:1232-52.

[10] Faggiani A, Falzon BG. Predicting low-velocity impact damage on a stiffened composite panel. Composites Part A: Applied Science and Manufacturing.

2010;41:737-49.

[11] Raimondo L, Iannucci L, Robinson P, Curtis PT. A progressive failure model for mesh-size-independent FE analysis of composite laminates subject to low-velocity impact damage. Composites Science and Technology. 2012;72:624-32.

[12] Huang J, Wang X. Numerical and experimental investigations on the axial crushing response of composite tubes. Composite Structures. 2009;91:222-8.

[13] Joosten MW, Dutton S, Kelly D, Thomson R. Experimental and numerical investigation of the crushing response of an open section composite energy absorbing element. Composite Structures. 2011;93:682-9.

[14] McCarthy MA, Wiggenraad JFM. Numerical investigation of a crash test of a composite helicopter subfloor structure. Composite Structures. 2001;51:345-59.

[15] Ghasemnejad H, Blackman BRK, Hadavinia H, Sudall B. Experimental studies on fracture characterisation and energy absorption of GFRP composite box structures. Composite Structures. 2009;88:253-61.

[16] Laffan MJ, Pinho ST, Robinson P, McMillan AJ. Translaminar fracture toughness testing of composites: A review. Polymer Testing. 2012;31:481-9.

[17] SIMULIA. Abaqus Documentation version 6.11: SIMULIA (Dassault Systems), 2011.

[18] Lau STW, Said MR, Yaakob MY. On the effect of geometrical designs and failure modes in composite axial crushing: A literature review. Composite Structures. 2012;94:803-12.

[19] Huang J, Wang X. On a new crush trigger for energy absorption of composite tubes. International Journal of Crashworthiness. 2010;15:625 - 34.

[20] Chiu LNS, Falzon BG, Ruan D, Xu S, Thomson RS, Chen B, et al. Crush responses of composite cylinder under quasi-static and dynamic loading. Composite Structures. 2015;131:90-8.

[21] Kassapoglou C. Design and Analysis of Composite Beams. Design and Analysis of Composite Structures: John Wiley \& Sons Ltd; 2013. p. 189-236.

[22] Feraboli P. Development of a Corrugated Test Specimen for Composite Materials Energy Absorption. Journal of Composite Materials. 2008;42:229-56. [23] Liu Z, Yang J, Grey F, Liu JZ, Liu Y, Wang Y, et al. Observation of Microscale Superlubricity in Graphite. Physical Review Letters. 2012;108. 
[24] Tsukizoe T, Ohmae N. Chapter 7 - Friction and Wear Performance of Unidirectionally Oriented Glass, Carbon, Aramid and Stainless Steel FiberReinforced Plastics. In: Klaus F, editor. Composite Materials Series: Elsevier; 1986. p. 205-31.

[25] Torres Arellano M, Crouzeix L, Collombet F, Douchin B, Grunevald Y-H. Mechanical Characterization of an Alternative Technique to Embed Sensors in Composite Structures: The Monitoring Patch. Applied Composite Materials. 2012;19:379-91.

[26] Chishti M, Wang CH, Thomson RS, Orifici AC. Characterising fibre compression fracture toughness of composites using bearing tests. Composites Part A: Applied Science and Manufacturing. 2012;43:1775-82.

[27] Caminero MA, Lopez-Pedrosa M, Pinna C, Soutis C. Damage monitoring and analysis of composite laminates with an open hole and adhesively bonded repairs using digital image correlation. Composites Part B: Engineering. 2013;53:76-91. [28] Ye Q, Chen P. Prediction of the cohesive strength for numerically simulating composite delamination via CZM-based FEM. Composites Part B: Engineering. 2011;42:1076-83.

[29] Falzon BG, Hawkins SC, Huynh CP, Radjef R, Brown C. An investigation of Mode I and Mode II fracture toughness enhancement using aligned carbon nanotubes forests at the crack interface. Composite Structures. 2013;106:65-73.

[30] Sokolinsky VS, Indermuehle KC, Hurtado JA. Numerical simulation of the crushing process of a corrugated composite plate. Composites Part A: Applied Science and Manufacturing. 2011;42:1119-26.

[31] Joosten MW. Experimental and Numerical Investigation of Triggered Composite Energy Absorbing Structures. University of New South Wales, Sydney, NSW, 2052, Australia: University of New South Wales, 2011.

[32] Preetamkumar M, Gilles L, Pierre L, Ana-cristina G. Validation of Intralaminar Behaviour of the Laminated Composites by Damage Mesomodel. 50th

AIAA/ASME/ASCE/AHS/ASC Structures, Structural Dynamics, and Materials

Conference: American Institute of Aeronautics and Astronautics; 2009.

[33] Ilyas M, Lachaud F, Espinosa C, Salaün M. Dynamic delamination of aeronautic structural composites by using cohesive finite elements. 17th International

Conference on Composite Materials (ICCM-17). Edinburgh, Scotland2009. 